\title{
Effects of carrying a pregnancy and of method of delivery on urinary incontinence: a prospective cohort study Erica Eason*1, Michel Labrecque ${ }^{2}$, Sylvie Marcoux ${ }^{3}$ and Myrto Mondor ${ }^{4}$
}

\begin{abstract}
Address: ${ }^{1}$ Dept. of Obstetrics \& Gynaecology, University of Ottawa, Ottawa, Canada, ${ }^{2}$ Dept. of Family Medicine, Université Laval, Québec, Canada, ${ }^{3}$ Dept. of Social and Preventive Medicine, Université Laval, Québec, Canada and ${ }^{4}$ Epidemiology research group, Centre hospitalier affilié universitaire de Québec, Hôpital St-Sacrement, Québec, Canada
\end{abstract}

Email: Erica Eason* - eeason@ohri.ca; Michel Labrecque - michel.labrecque@mfa.ulaval.ca; Sylvie Marcoux - sylvie.marcoux@fmed.ulaval.ca; Myrto Mondor - myrto.mondor@uresp.ulaval.ca

* Corresponding author

Published: 19 February 2004

BMC Pregnancy and Childbirth 2004, 4:4

This article is available from: http://www.biomedcentral.com/I47I-2393/4/4

(C) 2004 Eason et al; licensee BioMed Central Ltd. This is an Open Access article: verbatim copying and redistribution of this article are permitted in all media for any purpose, provided this notice is preserved along with the article's original URL.
Received: 25 September 2003

Accepted: 19 February 2004

\begin{abstract}
Background: This study was carried out to identify risk factors associated with urinary incontinence in women three months after giving birth.

Methods: Urinary incontinence before and during pregnancy was assessed at study enrolment early in the third trimester. Incontinence was re-assessed three months postpartum. Logistic regression analysis was used to assess the role of maternal and obstetric factors in causing postpartum urinary incontinence. This prospective cohort study in 949 pregnant women in Quebec, Canada was nested within a randomised controlled trial of prenatal perineal massage.

Results: Postpartum urinary incontinence was increased with prepregnancy incontinence (adjusted odds ratio [adjOR] 6.44, 95\% Cl 4.15, 9.98), incontinence beginning during pregnancy (adjOR I.93, 95\% Cl I.32, 2.83), and higher prepregnancy body mass index (adjOR I.07/unit of BMI, $95 \% \mathrm{Cl} \mathrm{I.03,} \mathrm{I.I} \mathrm{I).} \mathrm{Caesarean} \mathrm{section} \mathrm{was} \mathrm{highly} \mathrm{protective} \mathrm{(adjOR} 0.27,95 \% \mathrm{Cl} 0.14,0.50$ ). While there was a trend towards increasing incontinence with forceps delivery (adjOR I.73, 95\% Cl 0.96, 3.13) this was not statistically significant. The weight of the baby, episiotomy, the length of the second stage of labour, and epidural analgesia were not predictive of urinary incontinence. Nor was prenatal perineal massage, the randomised controlled trial intervention. When the analysis was limited to women having their first vaginal birth, the same risk factors were important, with similar adjusted odds ratios.
\end{abstract}

Conclusions: Urinary incontinence during pregnancy is extremely common, affecting over half of pregnant women. Urinary incontinence beginning during pregnancy roughly doubles the likelihood of urinary incontinence at 3 months postpartum, regardless whether delivery is vaginal or by Caesarean section.

\section{Background}

Bearing children is known to increase the likelihood of urinary incontinence, but which aspects of pregnancy and delivery cause urinary incontinence have not been clearly established. The role of pregnancy itself, independent of labor and delivery practices, in causing incontinence has not been adequately recognized. The risk of urinary stress incontinence is known to increase throughout pregnancy [1]. While most women incontinent during pregnancy will regain continence postpartum, those with 
postpartum incontinence will almost always have been incontinent during pregnancy [1-3]

The objectives of this study were to identify maternal and obstetrical factors associated with developing urinary incontinence during pregnancy; to describe the prevalence and severity of postpartum urinary incontinence; and to identify factors associated with postpartum incontinence.

\section{Methods}

Information for this study was collected during a randomised controlled trial of perineal massage during the third trimester of pregnancy $[4,5]$. The study population consisted of pregnant women with or without a previous vaginal birth delivering in five secondary and tertiary care hospitals in the province of Quebec, Canada. The study was approved by the ethics committees of each participating institution. Women were enrolled at 30 and 35 weeks gestational age. In the intervention group, women were taught to do a stretching massage of the perineum for 5 to 10 minutes daily from 34-35 weeks gestation until delivery; women in the control group were asked to refrain from perineal massage. There were 1527 women enrolled between September 1994 and December 1995. At enrolment, participants completed a questionnaire on sociodemographics and obstetrical history. Women recruited after March 1995 ( $\mathrm{n}=1198$ ) also completed a self-administered questionnaire on perineal functions during the month before conception and during the month before enrolment (i.e. early third trimester of pregnancy.) The questionnaire elicited information on the frequency (never, less than once per week, 1-6 times a week, once a day, more than once a day) of involuntary loss of urine when coughing, sneezing, laughing, or running. We asked this quantitative question about the frequency of stress incontinence since we were interested in the pathophysiology - actual episodes of urine loss - rather than the social impact of incontinence. At three months postpartum, a questionnaire was mailed to each participant asking about stress urinary incontinence at that point in time. Detailed data on the occurrence and severity of perineal lacerations and episiotomy were recorded immediately after the birth by the attending physician or house staff. The perineum was considered to be intact if there was no laceration or a non-sutured first-degree tear. Other information about the labour and delivery was abstracted from the medical record.

For the analysis of predictors of incontinence, incontinence was treated as dichotomous: any vs. no incontinence. Secondary analyses were carried out restricting the outcome to more severe incontinence - at least weekly and at least daily. To assess urinary incontinence before delivery as a predictor of postpartum incontinence, a cat- egorical variable was constructed with 3 levels: women with incontinence pre-pregnancy (95\% continued to be incontinent during pregnancy), new onset of incontinence during pregnancy, and no incontinence before or during this pregnancy. Maternal, obstetrical and newborn candidate variables for the adjusted models were identified by univariate odds ratios $(\mathrm{OR})<0.8$ or $>1.25$ in association with urinary incontinence, or from the medical literature. Univariate and adjusted odds ratios (adjOR) and their $95 \%$ confidence intervals (95\% CI) were obtained. Adjusted odds ratios from logistic regression analysis somewhat overestimate relative risk when the outcome is common. Since episiotomy and operative delivery are determinants ("in the causal pathway") of perineal trauma, separate models were used to analyse whether incontinence was better predicted by these interventions or by the degree of perineal trauma. Univariate, stratified and logistic regression analyses were carried out using Stata 7.0.

\section{Results}

Postpartum questionnaires were returned by 949 (79\%) of 1198 women. These women constitute the study population, which has been described in a previous publication [5]. Baseline maternal characteristics of responders and non-responders to the postpartum questionnaire were similar in most respects although women who did not return their postpartum questionnaires were slightly younger (mean age, 28.6 vs. 29.8 yr.), less educated (mean educational level, 14.3 vs. 15.8 yr.) and more likely to have given birth by Caesarean section $(17.7 \%$ vs. $12.0 \%)$. There was no difference in the proportion of responders between the perineal massage and control groups.

Urinary incontinence was experienced by $22.3 \%$ of women before pregnancy, $65.1 \%$ during the third trimester, and $31.1 \%$ three months after delivery. Table 1 details the frequency of urinary incontinence before, during and after pregnancy in women delivering by Caesarean section or having a first or a subsequent vaginal birth. Only 10 women were delivered by Caesarean after a previous vaginal birth; we excluded them from further analysis, since they were too few to provide reliable estimates of effect. The proportion of primiparous women delivered by Caesarean who experienced urinary incontinence before $(16.3 \%)$ and during pregnancy $(55.8 \%)$ was similar to that of primiparous women who delivered vaginally (16.1 and $58.9 \%$, respectively.) Postpartum though, 31.2\% of women were still incontinent after vaginal births compared to only $11.5 \%$ of women after Caesarean (OR 3.48, $95 \%$ CI $1.85,6.54$.) Of women expecting a first vaginal birth who remained continent during pregnancy, 20.6\% were incontinent after vaginal delivery compared to only 6.6\% after Caesarean (OR 3.64, 95\% CI 1.07, 12.34). 
Table I: Urinary stress incontinence before, during and $\mathbf{3}$ months after pregnancy in $\mathbf{8 3 5}$ women delivering vaginally without or with a previous vaginal birth, and in 104 primiparous women delivering by Caesarean.*

\begin{tabular}{|c|c|c|c|c|c|c|}
\hline & \multicolumn{6}{|c|}{ Urinary stress incontinence } \\
\hline & \multicolumn{2}{|c|}{ before pregnancy } & \multicolumn{2}{|c|}{ third trimester } & \multicolumn{2}{|c|}{3 mo. postpartum } \\
\hline & $\mathrm{N}$ & $\%$ & $\mathrm{~N}$ & $\%$ & $\mathrm{~N}$ & $\%$ \\
\hline \multicolumn{7}{|l|}{ | st vaginal birth $(\mathrm{N}=467)$} \\
\hline None & 392 & 83.9 & 190 & 41.1 & 322 & 68.8 \\
\hline Less than once per week & 62 & 13.3 & 168 & 36.4 & 99 & 21.2 \\
\hline One to six times per week & 6 & 1.3 & 72 & 15.6 & 34 & 7.3 \\
\hline Once daily & 4 & 0.9 & 17 & 3.7 & 8 & 1.7 \\
\hline More than once daily & 3 & 0.6 & 15 & 3.3 & 5 & I.I \\
\hline \multicolumn{7}{|c|}{ Repeat vaginal birth $(\mathrm{N}=367)$} \\
\hline None & 250 & 68.1 & 89 & 24.3 & 232 & 63.2 \\
\hline Less than once per week & 93 & 25.3 & 145 & 39.5 & 98 & 26.7 \\
\hline One to six times per week & 14 & 3.8 & 78 & 21.3 & 24 & 6.5 \\
\hline Once daily & 6 & 1.6 & 28 & 7.6 & 2 & 0.5 \\
\hline More than once daily & 4 & 1.1 & 27 & 7.4 & 11 & 3.0 \\
\hline \multicolumn{7}{|c|}{ | st Caesarean section $(N=104)$} \\
\hline None & 87 & 83.7 & 46 & 44.2 & 92 & 88.5 \\
\hline Less than once per week & 15 & 14.4 & 34 & 32.7 & 10 & 9.6 \\
\hline One to six times per week & 2 & 1.9 & 17 & 16.4 & I & 1.0 \\
\hline Once daily & 0 & 0 & 5 & 4.8 & i & 1.0 \\
\hline More than once daily & 0 & 0 & 2 & 1.9 & 0 & 0 \\
\hline
\end{tabular}

*Totals may vary due to missing data. Ten women with a previous vaginal birth who delivered by Caesarean are not described in this table.

Most $(81.8 \%)$ of the women with postpartum urinary incontinence were already incontinent before giving birth: 40.3\% (119/295) were already incontinent before pregnancy, $40.7 \%(120 / 295)$ developed incontinence by the third trimester, and $18.0 \%$ (53/295) between study enrolment and completion of the postpartum questionnaire (third trimester data missing for a few individuals.

Urinary incontinence occurred at least daily in $26 / 835$ (3.11\%) of women after vaginal birth and in $1 / 114$ $(0.88 \%)$ following Caesarean birth (risk difference $2.2 \%$, $95 \%$ CI $0.2 \%, 4.3 \%$ ). However, compared to those delivering by Caesarean, women delivering vaginally were more likely to have at least daily incontinence before $(2.0 \%$ vs. $0.9 \%)$ and during $(10.5 \%$ vs. $8.8 \%)$ the pregnancy, not just after giving birth (NS).

New onset of urinary incontinence during pregnancy was more frequent in parous compared to nulliparous women (OR 1.95, 95\% CI 1.42, 2.67). However maternal age, body mass index, weight gain during pregnancy, or factors potentially related to connective tissue properties, such as hair colour and stretch marks (data not shown) did not help to predict which women would develop urinary incontinence during pregnancy.
Postpartum urinary incontinence (three months after delivery) was independently associated with incontinence present before becoming pregnant and incontinence beginning during pregnancy (Table 2), even among women undergoing Caesarean birth. Postpartum urinary incontinence was associated strongly with high prepregnancy body mass index ( $7 \%$ for each unit of body mass index). Once pre-pregnancy incontinence was taken into account, parous women were not more likely than nulliparous women to be incontinent postpartum (see stratified analysis, Table 3 ). Caesarean section was protective (Table 2). The following factors were not significantly associated with postpartum urinary incontinence in adjusted (multivariate) models: age, weight gain during pregnancy, baby's weight, previous vaginal birth, randomization group (massage or control), type of delivery, epidural anesthesia, duration of second stage of labor, episiotomy (Table 2) or degree of perineal trauma or periurethral tears (data from this model not shown).

We repeat these analyses with 'incontinence at least weekly' instead of 'any incontinence' as the outcome; the same predictors were significant. Too few subjects had incontinence at least daily $(n=27)$ for stable estimates of odds ratios. Analyses restricted to women having a first vaginal birth yielded the same predictors as analysis with all parities combined. 
Table 2: Risk factors for any urinary incontinence three months postpartum

\begin{tabular}{|c|c|c|c|c|c|c|}
\hline Risk factors & $N$ & Risk (\%) & Crude OR & $95 \% \mathrm{Cl}$ & Adj. OR* & $95 \% \mathrm{Cl}$ \\
\hline \multicolumn{7}{|l|}{ Age (years) } \\
\hline$\leq 25$ & $|4|$ & 26 & 1.00 & - & & \\
\hline $26-29$ & 338 & 29 & 1.16 & $0.75, I .81$ & & \\
\hline $30-34$ & 356 & 32 & 1.29 & $0.83,2.00$ & & \\
\hline$\geq 35$ & 114 & 41 & 1.97 & I.16,3.35 & & \\
\hline Age (continuous) & & & 1.04 & $\mathrm{I} .0 \mathrm{I}, \mathrm{I} .07$ & 1.02 & $0.99,1.06$ \\
\hline \multicolumn{7}{|l|}{ Body mass index (BMI) $(\mathrm{kg} / \mathrm{m} 2)$} \\
\hline$<20.0$ & 216 & 25 & 1.00 & - & & \\
\hline $20.0-23.9$ & 442 & 30 & 1.31 & $0.90,1.89$ & & \\
\hline$\geq 24.0$ & 291 & 37 & 1.74 & $1.18,2.58$ & & \\
\hline BMI (continuous) & & & 1.05 & $1.02,1.09$ & 1.07 & $1.03,1.11$ \\
\hline \multicolumn{7}{|l|}{ Weight gain during pregnancy $(\mathrm{kg})$} \\
\hline$\leq \mathrm{II} .0$ & 268 & 31 & 1.00 & - & & \\
\hline $1 \mathrm{I} . \mathrm{I}-14.0$ & 272 & 30 & 0.93 & $0.64,1.34$ & & \\
\hline $14 .|-| 7.0$ & 194 & 35 & 1.18 & $0.80,1.75$ & & \\
\hline$>17.0$ & 215 & 29 & 0.89 & $0.60,1.31$ & & \\
\hline \multicolumn{7}{|l|}{ Baby's weight (g) } \\
\hline$<4000$ & 837 & 31 & 1.00 & - & & \\
\hline$\geq 4000$ & 112 & 30 & 0.96 & $0.73,1.48$ & & \\
\hline \multicolumn{7}{|l|}{ Previous vaginal birth } \\
\hline 0 & 572 & 28 & 1.00 & - & 1.00 & - \\
\hline$\geq 1$ & 377 & 36 & 1.50 & $1.13,1.98$ & 1.30 & $0.85,1.98$ \\
\hline \multicolumn{7}{|l|}{ Group of randomization } \\
\hline Controls & 478 & 33 & 1.00 & & & \\
\hline Massage & 470 & 29 & 0.85 & $0.65,1.12$ & & \\
\hline \multicolumn{7}{|l|}{ Urinary incontinence Before delivery } \\
\hline None & 319 & 17 & 1.00 & - & 1.00 & - \\
\hline Onset before Index pregnancy & 211 & 56 & 6.24 & $4.20,9.27$ & 6.44 & $4.15,9.98$ \\
\hline Onset during Index pregnancy & 412 & 29 & 1.98 & $1.39,2.83$ & 1.93 & $1.32,2.83$ \\
\hline \multicolumn{7}{|l|}{ Type of delivery } \\
\hline Spontaneous & 682 & 33 & 1.00 & - & 1.00 & - \\
\hline Vacuum & 79 & 35 & 1.11 & $0.68,1.80$ & 1.27 & $0.74,2.19$ \\
\hline Forceps & 74 & 37 & 1.16 & $0.70,1.91$ & 1.73 & $0.96,3.13$ \\
\hline Caesareanł‡ & 114 & 12 & 0.28 & $0.16,0.51$ & 0.27 & $0.14,0.50$ \\
\hline \multicolumn{7}{|l|}{ Epidural anesthesiał } \\
\hline No & 294 & 35 & 1.00 & - & & \\
\hline Yes & 541 & 33 & 0.93 & $0.69,1.26$ & & \\
\hline \multicolumn{7}{|l|}{ Duration of second Stage $(\mathrm{hrs}) \ddagger$} \\
\hline$<0.5$ & 317 & 39 & 1.00 & - & 1.00 & - \\
\hline $0.5-0.9$ & 175 & 31 & 0.71 & $0.48,1.06$ & 0.85 & $0.54,1.33$ \\
\hline $1.0-1.4$ & 127 & 31 & 0.71 & $0.46,1.10$ & 0.78 & $0.46,1.35$ \\
\hline$\geq 1.5$ & 216 & 31 & 0.71 & $0.49,1.0$ & 0.68 & $0.52,1.42$ \\
\hline \multicolumn{7}{|l|}{ Episiotomy $\ddagger$} \\
\hline No & 612 & 35 & 1.00 & - & 1.00 & - \\
\hline Yes & 223 & 29 & 0.75 & $0.54,1.05$ & 0.68 & $0.47,1.01$ \\
\hline
\end{tabular}

Total may vary because of missing values. *Adjusted for maternal age, body mass index, previous vaginal birth, timing of onset of urinary incontinence, type of delivery, duration of second stage, and episiotomy. łonly vaginal deliveries $(n=835)$ included $\ddagger \ddagger A d j u s t e d$ for maternal age, body mass index, previous vaginal birth, timing of onset of urinary incontinence, type of delivery

Incontinence worse after delivery than in the third trimester occurred in only $9.7 \%(91 / 943)$ of women. Worse incontinence occurred in $3.5 \%(4 / 114)$ of women after Caesarean (adjOR 0.28, 95\% CI 0.09,0.85) compared with $10.5 \%(87 / 829)$ after vaginal delivery. Maternal body mass index (adjOR 1.06 per unit of BMI, 95\% CI
$1.01,1.11$ ) was significantly associated with worsening of incontinence peripartum. Worsening tended to be more likely after forceps deliveries (adjOR 1.83, 95\% CI $0.99,3.37$ ) than after vacuum extraction (adjOR 1.33, $95 \%$ CI $0.73,2.42$ ) or spontaneous delivery. Maternal age, baby's weight, length of the second stage, episiotomy, per- 
Table 3: Proportion of women with urinary incontinence 3 months postpartum

\begin{tabular}{lccc}
\hline & \multicolumn{2}{l}{ Previous vaginal birth } & P value \\
\hline & None & One or more & \\
\hline Continent prepregnancy & $22.8 \%$ & $25.6 \%$ & $0.39 *$ \\
incontinent prepregnancy & $52.2 \%$ & $59.7 \%$ & $0.27^{*}$ \\
\hline
\end{tabular}

* Chi-square test

iurethral lacerations and degree of perineal trauma did not predict significant peripartum worsening of urinary incontinence.

\section{Discussion}

The $79 \%$ response rate to the postpartum questionnaire is very satisfactory for a single mailing. Although women experiencing urinary incontinence before or during the pregnancy were slightly more likely to respond, the availability of information on their antepartum continence status allowed us to control for this difference in the analysis. Women experiencing postpartum urinary incontinence may have been more or less likely to respond to the questionnaire but the direction of this potential bias is unclear. We used a quantitative question regarding the frequency of stress incontinence, since we were interested in actual episodes of urine loss. The question has been validated as part of the King's Health Questionnaire as a separately scored item [6]. While some questionnaires (e.g. Urogenital Distress Inventory) emphasise the social and hygienic impact of incontinence, actual urine loss, rather than women's adaptation to it, they are more pertinent to an exploration of causal factors. We did not address urge incontinence; Wilson [2] found no difference in predictors of different types of incontinence (any, stress or 'pure stress') at three months postpartum; they also found no relation between obstetrical factors and urinary frequency and nocturia.

This prospective study of 949 women highlights the magnitude of the problem of urinary incontinence during pregnancy. Although parous women are more likely to suffer from incontinence, a surprising proportion of women with no previous delivery by any route $(15.4 \%)$ reported that they had been incontinent before becoming pregnant. By the third trimester, over half of pregnant women anticipating a first vaginal birth and fully three quarters of women with a previous vaginal birth reported urinary incontinence. Since this information was collected at 30-34 weeks gestation, still more women may have become incontinent during the remaining weeks before delivery. In fact, serial interviews of pregnant women suggest that this is likely [7]. These figures are strikingly high, but of the same order as reported by Francis [3]. We found that just under a third of women after a first vaginal delivery and more than a third after a subsequent vaginal birth continue to have urinary incontinence three months later. The proportion of women remaining incontinent 3 months after a first vaginal delivery (31.2\%) is virtually identical to the proportion of parous women reporting incontinence just before the index pregnancy $(31.9 \%)$, suggesting that postpartum incontinence usually does not resolve over time. Only $2.8 \%$ of women after first vaginal births and 3.5\% after subsequent births had severe (at least daily) urinary incontinence, but the risk of urine loss even with less severe incontinence may constrict women's daily life.

Incontinence during pregnancy often resolves postpartum [3,7-9]. However, incontinence beginning during pregnancy is neither trivial - $13.6 \%$ of these women endured incontinence every day - nor transient: it indicates a significant risk of persistent urinary incontinence, even in women eventually delivered by Caesarean section. In fact, this prospective data confirms retrospective studies $[8,10]$ in finding that pregnancy-induced incontinence is one of the strongest predictors of postpartum incontinence regardless of the route of delivery. In fact, stress incontinence rarely appears for the first time after childbirth if it has not happened during the pregnancy $[3,7]$. Thus determining who is at risk of becoming incontinent during pregnancy would be helpful in targeting preventive interventions. Unfortunately, we were not able to identify predictive maternal characteristics. Consequently, measures such as pelvic floor exercises in pregnancy which decrease postpartum urinary incontinence [11] are best recommended to all pregnant women.

Incontinence was worse after delivery than before in less than $10 \%$ of women. This is an upper limit for the proportion of women whose incontinence was a result of the delivery, since some may have become incontinent between study enrolment and delivery. It is in the same range as found by others $[2,8,9,12]$. The protective effect of Caesarean delivery is consistent throughout the literature. Impairment of continence during pregnancy seems to be largely reversible unless the stresses of vaginal birth are superimposed.

Episiotomy was introduced in part to protect the pelvic floor and prevent urinary incontinence [13]. But our and others' work $[9,14-16]$ do not show a significant association between episiotomy and urinary incontinence. Avoiding episiotomy does increase periurethral tears [17] but we found that periurethral tears do not increase the risk of urinary incontinence. The relative risk for postpartum urinary incontinence after forceps delivery was con- 
sistent with a modest increase but the confidence limits included no increase in risk. Studies by Wilson [2] and Farrell [18] also found no increased risk with forceps deliveries. Vacuum extraction did not significantly increase risk. Despite concerns expressed by some obstetricians regarding perineal massage, this randomised controlled trial reassured us that the perineal stretching induced by massage neither impairs nor substantially protects against urinary continence [5]. Pelvic floor damage has been attributed to intrapartum events by Allen [19], who described neurophysiologic changes in association with a long second stage and larger babies. However, we and others $[2,8,18]$ found that birthweight and the length of the second stage did not contribute to postpartum urinary incontinence. As shown in Table 2, even in women having a first vaginal birth, there was no trend towards incontinence with increasing length of the second stage or macrosomia. This was true both in univariate analysis and after adjustment for potentially confounding factors such as operative vaginal delivery or degree of perineal trauma. We unfortunately cannot comment on the duration of active pushing in the second stage, since we did not collect this information.

\section{Conclusions}

Being pregnant causes urinary incontinence in the majority of women, and increases the risk of postpartum urinary incontinence whether delivery is vaginal or by Caesarean. However, Caesarean delivery is associated with a lower absolute risk of postpartum urinary incontinence.

\section{Competing interests}

\section{None declared.}

\section{Authors' contributions}

EE and ML conceived of and designed the study, designed the draft questionnaires, coordinated the study and drafted the manuscript. MM and SL helped to design the study, performed the statistical analyses and participated in drafting the manuscript. All authors read and approved the final manuscript.

\section{Acknowledgements}

Support for this study was provided by the Medical Research Council of Canada and the Fonds de la recherche en santé du Québec. Organon Canada supported investigator workshops. Dr. Marcoux holds a National Health Research Scholarship from Health Canada. Dr. Labrecque held a Research Fellowship from Medical Research Council of Canada.

\section{References}

I. Thorp JM Jr, Norton PA, Wall LL, Kuller JA, Eucker B, Wells E: Urinary incontinence in pregnancy and the puerperium: a prospective study. Am J Obstet Gynecol 1999, 181:266-273.

2. Wilson PD, Herbison RM, Herbison GP: Obstetric practice and the prevalence of urinary incontinence three months after delivery. Br J Obstet Gynaecol 1996, I03:154-161.

3. Francis WJA: The onset of stress incontinence. J Obstet Gynaecol Br Empire 1960, 67:899-903.
4. Labrecque M, Eason E, Marcoux S, Lemieux F, Pinault J-J, Feldman P, Laperriere L: Randomised controlled trial of prevention of perineal trauma by perineal massage during pregnancy. $A m \mathrm{~J}$ Obstet Gynecol I 999, 1 80:593-600.

5. Labrecque M, Eason E, Marcoux S: Randomised trial of perineal massage during pregnancy: perineal symptoms three months after delivery. Am J Obstet Gynecol 2000, 182:76-80.

6. Kelleher CJ, Cardozo LD, Khullar V, Salvatore S: A new questionnaire to asses the quality of life of urinary incontinent women. Br J Obstet Gynaecol 1997, 104:1374-1379.

7. Stanton SL, Kerr-Wilson R, Harris VG: The incidence of urological symptoms in normal pregnancy. Br J Obstet Gynaecol 1980, 87:897-900.

8. losif $\mathrm{S}$ : Stress incontinence during pregnancy and in puerperium. Int J Gynaecol Obstet I98I, 19:| 3-20.

9. Viktrup L, Lose G, Rolff M, Barfoed K: The symptom of stress incontinence caused by pregnancy or delivery in primiparas. Obstet Gynecol 1992, 79:945-949.

10. Meyer S, Schreyer A, de Grandi P, Hohlfeld P: The effects of birth on urinary continence mechanisms and other pelvic-floor characteristics. Obstet Gynecol 1998, 92:613-618.

II. Harvey MA: Pelvic floor exercises during and after pregnancy: a systematic review of their role in preventing pelvic floor dysfunction. J Obstet Gynaecol Can 2003, 25:487-498.

12. Chaliha C, Kalia V, Stanton SL, Monga A, Sultan AH: Antenatal prediction of postpartum urinary and fecal incontinence. Obstet Gynecol 1999, 94:689-694.

13. Farrell SA, Allen VM, Baskett TF: Parturition and urinary incontinence in primiparas. Obstet Gynecol 200I, 97:350-356.

14. Cunningham FG, Macdonald PC, Gant NF, Leveno KJ, Gilstrap LC, Hankins GDV: Williams Obstetrics. 20th edition. Stamford, Conn: Appleton\&Lange; 1997.

15. Klein MC, Gauthier RJ, Jorgensen SH, Robbins JM, Kaczorowski J, Johnson B, Corriveau M, Westreich R, Waghorn K, Gelfand M, Guralnick MS, Luskey GW, Joshi AK: Does episiotomy prevent perineal trauma and pelvic floor relaxation? Online $j$ Curr Clin Trials 1992, I:Doc No 10.

16. Sleep J, Grant A: West Berkshire perlneal management trial: three year follow-up. Br Med J 1987, 295:749-75I.

17. Rockner G: Urinary incontinence after perineal trauma at childbirth. Scand J Caring Sci 1990, 4:169-172.

18. Carroli G, Belizan J, Stamp G: Episiotomy policies in vaginal births. In: Pregnancy and Childbirth Module of The Cochrane Database of Systematic Reviews Edited by: Neilson JP, Crowther CA, Hodnett ED, Hofmeyr GJ. Oxford: Oxford:Update Software; 1998.

19. Allen RE, Hosker GL, Smith ARB, Warrell DW: Pelvic floor damage and childbirth: a neurophysiological study. $\mathrm{Br} J$ Obstet Gynaecol 1990, 97:770-779.

\section{Pre-publication history}

The pre-publication history for this paper can be accessed here:

http://www.biomedcentral.com/1471-2393/4/4/prepub

Publish with BioMed Central and every scientist can read your work free of charge

"BioMed Central will be the most significant development for disseminating the results of biomedical research in our lifetime. "

Sir Paul Nurse, Cancer Research UK

Your research papers will be:

- available free of charge to the entire biomedical community

- peer reviewed and published immediately upon acceptance

- cited in PubMed and archived on PubMed Central

- yours - you keep the copyright

Submit your manuscript here:

http://www.biomedcentral.com/info/publishing_adv.asp
BioMedcentral 